\title{
A cold of the soul: A Japanese case of disease mongering in psychiatry
}

\author{
Hiroshi Ihara* \\ Department of Psychiatry, Dokkyo Medical University Koshigaya Hospital, Koshigaya, Japan
}

\begin{abstract}
In Japan, depression provides the most drastic example of the impact of disease awareness campaigns. Until the late $1990 \mathrm{~s}$, the public's attitude toward depression was generally unfavorable, due to the negative connotations of the Japanese word for clinical depression, 'utsubyou'. After the 1999 introduction of the first selective serotonin re-uptake inhibitor, pharmaceutical companies initiated educational campaigns. In order to aid the drug's acceptance, they coined the catchphrase 'kokoro no kaze', which literally means 'a cold of the soul'. Thanks to these marketing practices, antidepressant sales have increased six fold, from $¥ 14.5$ billion in 1998 to $¥ 87$ billion in 2006 .

However, the catchphrase 'kokoro no kaze' masked a critical difference between a cold and depression. It falsified the nature of treatment for depression by concealing the putative duration of medication. Owing to this distortion of information, pharmaceutical companies were assured a steady stream of profits.

Now, the pharmaceutical industry is shifting its focus from depression to bipolar disorder. Japanese psychiatrists can learn a great deal from their experience with the aggressive marketing of antidepressants. In the case of depression, over-medication arguably did more harm than good. The same risk exists with other conditions, including bipolar disorder.

Keywords: Selective serotonin reuptake inhibitors (SSRIs), depression, disease mongering, pharmaceutical industry, Japan
\end{abstract}

\section{Introduction}

Disease mongering has recently begun to have an adverse influence on both psychiatrists and patients in Japan. Indeed, this problem has been widely discussed internationally. [9, 17, 21]. But, there has been a relative paucity of reports concerning the current state of disease mongering in Japan, due perhaps to a language barrier. This paper will discuss disease mongering in the Japanese context, with a particular focus on depression.

\section{Disease mongering}

Frequently used in a uncomplimentary sense, disease mongering connotes a widening of the diagnostic boundaries of illness. It is most often employed for activities of pharmaceutical companies, or others with similar interests, who conduct disease awareness campaigns on the pretext of educating the public about the prevention of illness or the promotion of health. Under the cover of early detection and early

\footnotetext{
*Address for correspondence: Prof. Hiroshi Ihara, MD, PhD, Department of Psychiatry, Dokkyo Medical University Koshigaya Hospital, 2-1-50 Minami-Koshigaya, Saitama Prefecture, 343-8555 Koshigaya City, Japan. Tel.: +81 48 965 1111; E-mail: cotoncb@dokkyomed.ac.jp.
} 
treatment, they strain the conceptual domain of diagnostic categories to their own advantage. Encouraged by these disease awareness advertisements, the public gradually becomes concerned that they are ill and require medical treatment. As a result, pharmacotherapy is increasingly being applied to ever-milder conditions, leading to potentially unnecessary medication, wasted resources, and adverse side effects [9, $17,21]$.

Proponents of these practices justify disease awareness campaigns, arguing that pharmaceutical industry is simply providing the public with information about its options and that the option of receiving medication is a matter to be discussed between patient and physician. Opponents however refute this argument, claiming that the true intent of disease awareness campaigns is primarily or even exclusively to produce profit for the drug companies. Furthermore, opponents suggest that by inspiring fear of illness, these campaigns drive patients to demand potentially unnecessary prescriptions, which may have unfavorable consequences instead of benefits [18].

Among all fields of clinical medicine, psychiatry is perhaps the most vulnerable to the dangers of disease mongering. The psychiatric conditions most commonly targeted by the pharmaceutical industry include social anxiety disorder, ADHD, bipolar disorder, and depression [15].

\section{Depression mongering in Japan}

\subsection{Depression before SSRI in Japan}

Until the late 1990 s, Japanese psychiatrists focused almost exclusively on psychosis and endogenous depression, the latter being severe enough to require conventional forms of antidepressants, known as tricyclic antidepressants, and even hospitalization [1,11].

At this time, the public's attitude toward depression was generally unfavorable. This stigma was in part due to the negative connotations of the Japanese word for clinical depression, 'utsubyou'. This word, which suggests severe mental illness, contrasts strikingly with the English word 'depression', which has a much broader meaning. Even in the psychiatric context, 'depression' can be used alongside various subdivisions: organic, endogenous, neurotic, major, minor, reactive, vascular, juvenile, postpartum, premenstrual, senile, etc.

'Utsubyou', on the other hand, means only major depressive disorder or the depressive phase in manicdepressive disorder. It is a highly technical term and is almost unheard of outside clinical medicine. To talk about a feeling of gloominess, the general public uses a variety of everyday expressions such as ' $\mathrm{ki} g \mathrm{a}$ omoi' (heavy spirit), 'ki ga harenai' (cloudy mood), 'ki ga meiru' (dented mood), and so on. Even when relying on the so-called psychiatric vocabulary, people prefer the term 'noiroze', a Japanized adaptation of the German word 'Neurose'.

In the past and also now, Japan's culture is strongly influenced by a Confucian tradition characterized by family centered and socio-centered attitudes and collectivism [19]. Over time, a worldview that encourages the acceptance of sadness, even the sharing of life's miseries with others, has emerged [22]. In Japan, it was natural that mild depression was rarely seen as a medical condition, and it was never thought that such feelings should be counteracted with chemical substances.

\subsection{Depression after SSRI in Japan}

This situation began to change after the 1999 introduction of Fluvoxamine (Luvox-Fujisawa, DepromelMeiji Seika), the first selective serotonin re-uptake inhibitor (SSRI) to receive approval in Japan. 


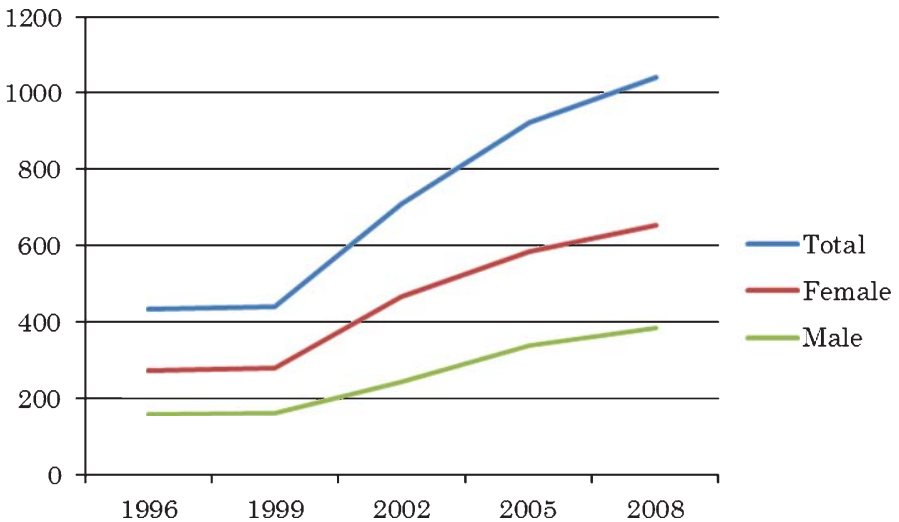

Fig. 1. National trends in patients with a diagnosis of mood disorder (thousands) (Ministry of Health and Welfare).

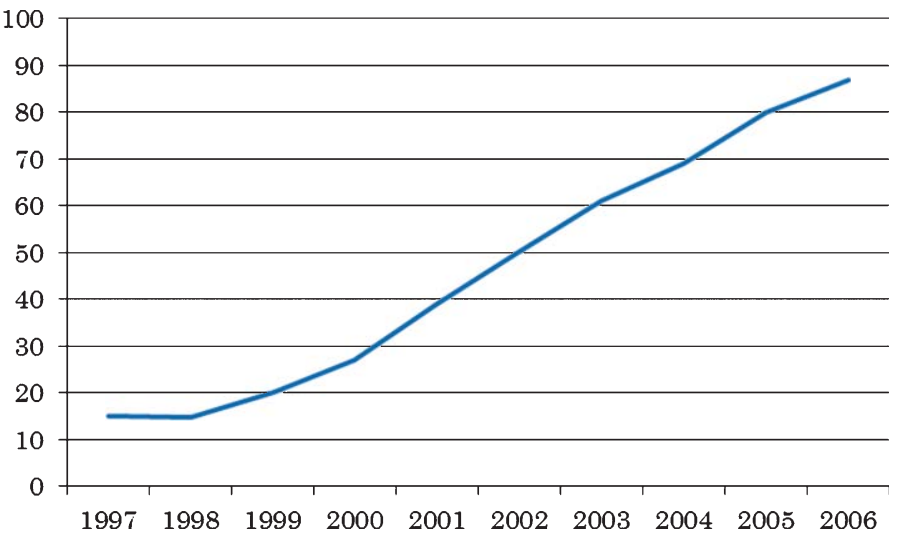

Fig. 2. Antidepressant sales in Japan (Billion Yen): Settlement of accounts (GlaxoSmithKline).

Direct-to-consumer advertising (DTC advertising) is prohibited in Japan, and so pharmaceutical companies initiated educational campaigns focusing on mild depression. In order to aid the drug's acceptance by the Japanese public, they coined the catchphrase 'kokoro no kaze', which literally means 'a cold of the soul' [14]. Thus armed with this phrase, the pharmaceutical industry embarked on a mission to lessen the stigma of depression [10].

The campaign accelerated when GlaxoSmithKline received approval for another SSRI, Paxil (paroxetine) [25]. Subsequently, sertraline (J-Zoloft-Pfizer), milnacipran (Toledomin-Asahi Kasei-Janssen) and duloxetin (Cymbalta-Eli Lilly) have also entered the market in Japan. According to national data from the Ministry of Health and Welfare [16], the number of patients with a diagnosis of mood disorder increased from 441,000 in 1999 to 1,041,000 in 2003 (Fig. 1). At the same time, antidepressant sales have increase six fold, from $¥ 14.5$ billion in 1998 to $¥ 87$ billion in 2006, according to statistics from GlaxoSmithKline (Fig. 2) [7, 24]. Thanks to marketing practices that equate depression with a cold, Japan has proven to be fertile ground for selling antidepressants. 


\section{3. 'A cold of the soul': A Japanese case of depression mongering}

The catchphrase 'kokoro no kaze' or 'a cold of the soul' masks a critical difference between the common cold and depression [3]. While medicines for the former are taken for a few days at most, those for the latter are usually consumed for months, years, or even for life. Thus, as patients began to see antidepressants as medicine for 'a cold of the soul', they became more likely to justify pharmacological treatment. However, once psychiatrists began prescribing antidepressants, they took for granted that their patients would be under treatment for months or much longer [2, 20, 23]. Indeed, once patients have begun to take antidepressants, many cannot help but continue. In this sense, the pharmaceutical companies' marketing claims falsified the nature of treatment for depression by concealing the documented duration of medication. Thanks to this distortion of information, pharmaceutical companies were assured a steady stream of profits.

These depression awareness campaigns have been based on the syllogism: "Your depression may be a disease. It can be cured by antidepressants. Therefore, your depression should be cured by antidepressants". This psychopharmacological reasoning is, even if valid, applicable only to the biological aspects of depression. It is utterly absurd to claim that antidepressants can cure depression caused by family difficulties, a dissolved relationship, a demanding job, or intractable indebtedness.

The neglect of psychotherapy has also contributed to the spike in antidepressant usage. Patients are frequently given only one option: pharmacotherapy. In fact, much variability exists among sufferers of depression. For some, depression is not linked to a chemical imbalance but rather is associated with inescapable life events such as separation, interpersonal conflicts, and unexpected adversities that are central to being human. Treatment should hence be multifaceted rather than depending solely on antidepressants. Patients, however, face difficulty in finding psychiatrists familiar with psychotherapy as well as with antidepressants.

\subsection{The pharmacological model of depression}

Perhaps most importantly, the pharmacological model of depression lacks a robust scientific foundation. Indeed, pharmacological treatment is based on the assumption that depression is caused by an imbalance of mood-regulating chemicals in the brain, although there is actually little evidence that the pharmacological model is really adequate for patients with less severe depression [13].

Recent meta-analyses $[5,12]$ have also called into question previous research, which postulated that antidepressants have a specific pharmacological effect in comparison to placebo in patients with mild to moderate symptoms. According to these meta-analyses, the benefit of medication relative to placebo depends on the initial severity of depression symptoms. Excluding patients with very severe depression, the benefit of medication over a placebo may be minimal or even nonexistent.

\section{Conclusions}

Japanese psychiatrists can learn a great deal from their experience with the aggressive marketing of antidepressants. It can be argued that in the case of depression, over-medication did more harm than good. The same risk exists with other conditions, including bipolar disorder, to which the pharmaceutical industry has recently been shifting its focus [4]. Disease mongering may occur whenever the interests of 
a pharmaceutical company exceed the expected benefits from the proposed pharmacotherapy on those affected by the putative psychiatric disorder. In cases that are not severe enough for aggressive medication, psychiatrists should propose natural alternatives, such as an alteration of lifestyle and psychotherapy $[6,8]$.

\section{Conflict of interest}

The author declares no conflict of interest.

\section{Acknowledgements}

This work was supported in part by Juntendo Institute of Psychiatry (H23 Kenkyu Joseikin).

\section{References}

[1] K. Appelbaum, Educating for global mental health. The adoption of SSRI's in Japan, In: Petryna A, Lakoff A, Kleinman A (Eds.). Global Pharmaceuticals: Ethics, Markets, Practices. Duke University Press, Durham, NC, 2006, pp. 85-110.

[2] M. Bauer, T. Bachor, A. Pfenning, et al., World Federation of Societies of Biological Psychiatry (WFSBP) guidelines for biological treatment of unipolar depressive disorders in primary care, The World Journal of Biological Psychiatry 8(2) (2007), 67-104.

[3] A. Brady, Film explores antidepressant use in Japan. The Japan Times, 2007. Available from: http://www.japantimes.co.jp/print/nn20070712f3.html

[4] Elli Lilly, Advertisement of Olanzapine, Seishinka Chiryogaku (Psychiatric Practice) 25(11) (2010), page not specified. (in Japanese).

[5] J.C. Fournier, R.J. DeRubeis, S.D. Hollon, A. Dimidjian, J.D. Amsterdam, R.C. Shelton and J. Fawcett, Anti depressant drug effects and depression severity. A patient-level meta-analysis, JAMA 303(1) (2010), 47-53.

[6] E. Frank, H.A. Swartz and D.J. Kupfer, Interpersonal and Social rhythm therapy: Managing the chaos of bipolar disorder, Biol Psychiatry 48 (2000), 593-604.

[7] Glaxo Smith-Kline. Paxil.jp Utsu Huan Saito (the Site of Depression and Anxiety) (in Japanese), 2008. Available from: http://paxil.jp/expert/exarchive/current_0805_1.php

[8] F. Goodwin and K. Jamison, Manic-Depressive Illness, Second Edition. Oxford University Press, New York, 2007, pp. 869-906.

[9] D. Healy, The latest mania: Selling bipolar disorder, PLoS Medicine 3 (2006), e185, 441-444.

[10] E. Ingrams, Long-taboo. 'mood disorder' is now being seen as the common and crippling disease it is, The Japan Times 10 (2005), http://www.japantimes.co.jp/text/fl20050710x1.html

[11] L.J. Kirmayer, Psychopharmacology in a globalizing world: The use of antidepressants in Japan, Transcultural Psychiatry 39 (2002), 295-322.

[12] I. Kirsch, B.J. Deacon, T.B. Huedo-Medina, A. Scoboria, T.J. Moore and B.T. Johnson, Initial severity and antidepressant benefits. A meta-analysis of data submitted to the Food and Drug Administration, PLoS Medicine 5 (2008), 250-268.

[13] L.R. Lacasse and J. Leo, Serotonin and depression. A disconnect between the advertisements and the scientific literature, PLoS Medicine 2 (2005), e392, 1211-1216.

[14] P. Landers, Drug companies push Japan to change view of depression, Wall Street Journal Online, 2002, http://www. chelationtherapyonline.com/technical/p98.htm

[15] C. Lane, Shyness: How normal behavior became a sickness. Yale University Press, New Haven, 2007.

[16] Ministry of Health, Labour and Welfare. Heisei 20 nen Kanja Chosa (The investigation of patients in 2008) (in Japanese), 2008. Available from: http://www.mhlw.go.jp/toukei/saikin/hw/kanja/10syoubyo/suiihyo18.html

[17] R. Moynihan, E. Doran and D. Henry, Disease mongering is now part of the global health debate, PLoS Med 5 (2008), e106. 
[18] R. Moynihan, I. Heath and D. Henry, Selling sickness. The pharmaceutical industry and disease mongering, $B M J 324$ (2002), 886-891.

[19] C. Nakane, Tate Shakai no Ningen Kankei, Human relationships in the vertical society. Kodansha, Tokyo, 1967.

[20] National Institute for Health and Clinical Excellence: The treatment and management of depression in adults, 2009. Available at: http://www.nice.org.uk/nicemedia/live/12329/45888/45888.pdf

[21] A. Saddichha, Disease mongering in psychiatry. Is it fact or fiction? World Medical \& Health Policy 2 (2010), 15.

[22] K. Schultz, Did antidepressants depress Japan? New York Times, 2004, http://www.nytimes.com/2004/08/22/magazine/ 22DEPRESS.html?ex=1250913600\&en=cbf6990f7aecfcc7\&ei=5090\&partner=rssuserland\&pagewanted=all

[23] TMAP (Texas Medications Algorithm Project) Manuals and algorithms: Major depressive disorder nonpsychotic algorithm, 2008. Available at: http://www:dshs.state.tx.us/mhprograms/pdf/TIMA_MDD_MDDAlgoOnly_080608.pdf

[24] S. Tomitaka Naze Utsu No Hito Ga Hueta Noka (in Japanese), Why did Depressed Patients Increase? Gentosha, Tokyo, 2009.

[25] E. Watters, How big pharma changed the nature of depression in Japan. The Scavenger, 2010, http://www. thescavenger.net/health/how-big-pharma-changed-the-nature-of-depression-in-japan-78235-466.html 